\title{
PENERAPAN SISTEM KEAMANAN DENGAN KRIPTOGRAFI ADVANCED ENCRYPTION STANDARD (AES) DAN KEY ADMINISTRATOR PADA SINKRONISASI FILE
}

\author{
Wawan Qurniawan, Hero Wintolo, Dwi Nugraheny \\ Teknik Informatika STTA Yogyakarta \\ informatika@stta.ac.id
}

\begin{abstract}
File synchronization is the process of homogenization or adjustment between one file at a location with other files in the event that a change to be used up and running in a system. File synchronization is generally a process of data exchange in order to have the same amount of data. To maintain the confidentiality of the data necessary to maintain services for data security.

The use of cryptographic AES (Advanced Encryption Standard) to encrypt the file and combined with the administrator as an authentication key in making additions or changes to the file is a security system that can be applied to synchronize the files so that data confidentiality will be maintained.

The results of the implementation of file synchronization application by applying the AES cryptography and key administrators who carried on the local network and the Internet as a service application data synchronization between the user and the service back-up data as manual handling if storage was damaged and can avoid the theft of data from a file synchronized.
\end{abstract}

Keywords: file synchronization, security systems, cryptography AES, administrator key, Rijndael algorithm

\section{Pendahuluan}

Kebutuhan akan informasi yang realtime saat ini merupakan salah satu kebutuhan yang tak terelakan lagi. Hal ini menunjukkan bahwa minat masyarakat untuk mencari dan bertukar informasi melalui internet semakin meningkat. Peningkatan ini menjadi salah satu komoditi yang dimanfaatkan oleh sebagian manusia, misalnya dalam hal penyimpanan data. Penyimpanan data di internet saat ini menggantikan penyimpanan manual yang biasa dilakukan, misalnya didalam hardisk, Compact Disc (CD), maupun flashdisk yang rentan terhadap kerusakan.

Semakin meningkatnya layanan internet yang diberikan semakin meningkat pula kebutuhan seseorang akan layanan tersebut. Kebutuhan akan data yang dapat diakses dari berbagai ruang kerja dan komputer, sehingga memungkinkan pengguna dapat mengakses datanya dari tempat yang berbeda, selama mereka terhubung dalam jaringan internet tanpa harus melakukan proses upload dan download setiap ingin mengakses file tersebut. Namun internet juga merupakan tempat dimana semua orang dapat mengaksesnya, untuk kepentingan yang baik maupun sebaliknya. Sehingga memunculkan kekhawatiran pengguna internet dalam melakukan penyimpanan maupun pertukaran data didalamnya. Sehingga diperlukan layanan untuk menjaga keamanan data tersebut. 
Sinkronisasi file merupakan salah satu cara agar file ataupun data pengguna akan selalu konsisten satu sama lainnya tanpa harus melakukan pengecekan file secara manual. Dan juga, file tersimpan di jaringan internet memungkinkan pengguna dapat mengakses kapan pun dan dimanapun. Didalam sinkronisasi file, penggunaan kriptografi merupakan salah satu sistem pengamanan data. Penggunaan kriptografi AES (Advanced Encryption Standard) dalam mengenkripsi file dan dikombinasikan dengan key administrator sebagai otentifikasi dalam melakukan penambahan atau perubahan file merupakan salah satu sistem keamanan yang dapat diterapkan pada sinkronisasi file sehingga kerahasiaan akan data tersebut dapat terjaga.

Dalam proses sinkronisasi file tidak menimbulkan permasalahan yang rumit apabila dilakukan peer-to-peer antar 2 komputer secara langsung, tetapi jika dilakukan pada jaringan komputer yang komplek seperti internet dengan memanfaatkan sebuah server akan menimbulkan masalah. Permasalahan yang timbul adalah dapatkah file yang ada di komputer satu dapat tersinkronisasikan dengan komputer lainnya dengan memanfaatkan server yang ada di intenet dan tetap terjaga keamanannya. Oleh karena itu perancangan aplikasi sinkronisasi file dengan menerapkan sistem keamanan kriptografi AES ini akan dikaji dan diteliti lebih mendalam untuk meminimalisir pengaruh yang muncul selanjutnya.

\section{Landasan Teori}

\subsection{Sinkronisasi File}

Sinkronisasi adalah proses pengaturan jalannya beberapa proses pada saat yang bersaman. Tujuan utama sinkronisasi adalah menghindari terjadinya inkonsistensi data dan untuk mengatur jalannya proses-proses sehingga dapat berjalan dengan lancar dan terhindar dari deadlock (Stalling2001). Sinkronisasi umumnya dilakukan dengan bantuan suatu perangkat atau aplikasi sinkronisasi.

Sinkronisasi file adalah proses penyeragaman atau penyesuaian antara satu file pada satu lokasi dengan file lainnya bila mengalami perubahan agar bisa digunakan dan berjalan dalam suatu sistem tertentu secara realtime. Sinkronisasi file pada umumnya merupakan proses pertukaran data agar memiliki jumlah data yang sama dan bertujuan sebagai layanan back-up data ke suatu media tertentu. Sinkronisasi dapat berjalan dalam berbagai protokol jaringan komputer, misalnya FTP (File Transfer Protocol).

\subsection{Kriptografi AES}

Kriptografi merupakan sebuah kata serapan dari bahasa asing, dalam hal ini bahasa inggris, yaitu cryptography. Cryptography atau cryptology berasal dari bahasa Yunani, yaitu kryptos (tersembunyi) dan graphō (menulis). Kriptografi adalah ilmu atau seni untuk menyembunyikan suatu informasi. Proses menyembunyikan informasi ini dilakukan dengan teknik penyandian, atau mengubah pesan atau informasi menjadi sandi-sandi yang tidak dimengerti oleh orang lain, selain pembuat dan penerimanya.

Advanced Encryption Standart (AES) adalah acuan yang dipakai sebagai standar algoritma kriptografi pada masa sekarang. Kriptografi AES merupakan pengganti dari kriptografi DES (Data Encryption Standard), Karena algoritma DES sudah dianggap tidak aman lagi. National Institute of Standard and Technology (NIST) sebagai Agensi Perdagangan AS menetapkan algoritma Rijndael sebagai algoritma standar yang dipakai pada kriptografi AES atau kriptografi kunci simetris modern. 
Algoritma Rijndael menggunakan substitusi, permutasi, dan sejumlah putaran yang dikenakan pada tiap blok yang akan dienkripsi atau didekripsi. Untuk setiap putarannya, Rijndael menggunakan kunci yang berbeda. Kunci setiap putaran disebut round key. Tetapi tidak seperti DES yang berorientasi bit, Rijndael beroperasi dalam orientasi byte, sehingga memungkinkan untuk implementasi algoritma yang efisien ke dalam software dan hardware. Ukuran blok untuk algoritma Rijndael adalah 128 bit (16 byte).

Algoritma Rijndael dapat mendukung panjang kunci 128 bit sampai 256 bit dengan step 32 bit. Panjang kunci berpengaruh pada jumlah putaran yang dikenakan pada tiap blok. Misalnya, untuk ukuran blok dan panjang kunci sebesar 128 bit ditentukan 10 putaran, sedangkan untuk ukuran blok 128 bit dan panjang kunci 256 bit jumlah putaran yang ditentukan adalah 14 putaran.

\subsection{Key Administrator}

Key administrator berasal dari istilah yang diambil dari kata key yang berarti kata kunci dan kata administrator yang berarti sesuatu yang dapat mengelola dan mempunyai hak akses secara penuh terhadap suatu sistem tertentu. Key Administrator merupakan kata kunci yang digunakan sebagai otentifikasi dalam melakukan perubahan maupun penambahan terhadap file yang disinkronsasikan. Key ini tersimpan di registry windows dan dienkripsi dengan MD5 memungkinkan keamanan akan tetap terjaga.

\section{Perancangan}

\subsection{Kebutuhan Perangkat Keras}

Hardware atau perangkat keras merupakan suatu komponen yang sangat mendukung dalam proses komputerisasi. Hardware berperan dalam input data, proses, dan menampilkan output. Berikut ini adalah spesifikasi hardware yang digunakan dalam membuat aplikasi ini:

1. Processor Intel Core 2 Duo

2. RAM 1 GB,

3. Harddisk $150 \mathrm{~GB}$,

4. Keyboard dan mouse standar.

\subsection{Kebutuhan Perangkat Lunak}

Adapun spesifikasi software atau perangkat lunak yang digunakan dalam pembuatan aplikasi ini adalah :

1. Sistem Operasi Windows 7 Ultimate

2. Delphi 7.0

3. XAMPP 1.7.1

4. Komponen Zeos Database Connector

5. FTP Server

\subsection{Sistem Flowchart}

Rancangan ini digunakan untuk mendesain dan merepresentasikan suatu program. Sebelum pembuatan program, fungsinya adalah mempermudah dalam menentukan alur logika program yang akan dibuat. Sesudah pembuatan program fungsinya adalah untuk menjelaskan alur program kepada orang lain atau user. 
Pada rancangan flowchart aplikasi penerapan kriptografi AES pada sinkronisasi file terdiri dari 3 bagian, yaitu proses registrasi user, proses sinkronisasi dan proses enkripsi deskripsi. Rancangan ini dapat dilihat pada gambar 1.

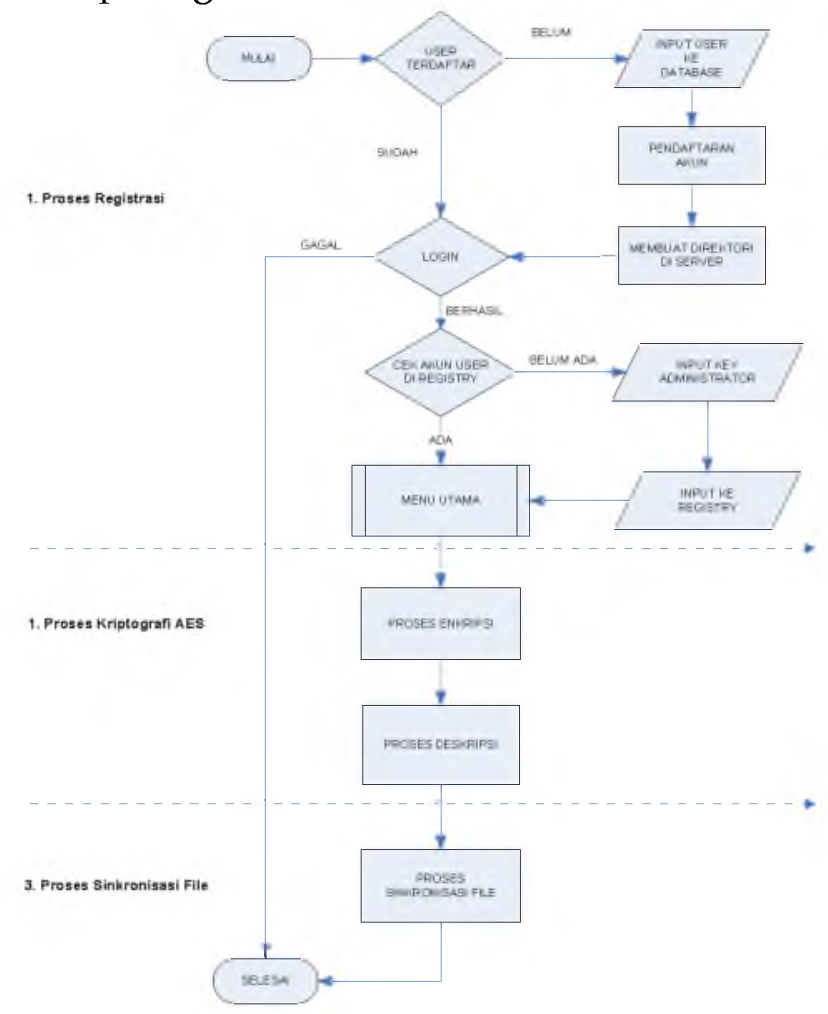

Gambar 1 Perancangan Flowchar Penerapan Kriptografi AES dan Key Administrator pada Aplikasi Sinkronisasi File

\subsection{Perancangan Antar Muka}

Perancangan tampilan utama aplikasi sinkronisasi file dengan menerapkan kriptografi AES dan key administrator seperti pada gambar 1. Rancangan tersebut terdiri dari 3 bagian, yaitu tombol Mulai Sinkronisasi dan identitas computer yang digunakan untuk melakukan proses sinkronisasi, daftar file digunakan untuk menampilkan daftar list file yang disinkronsasikan, input file digunakan untuk memasukkan data ke dalam daftar file. Tampilan rancangan tesebut seperti pada gambar 2 .

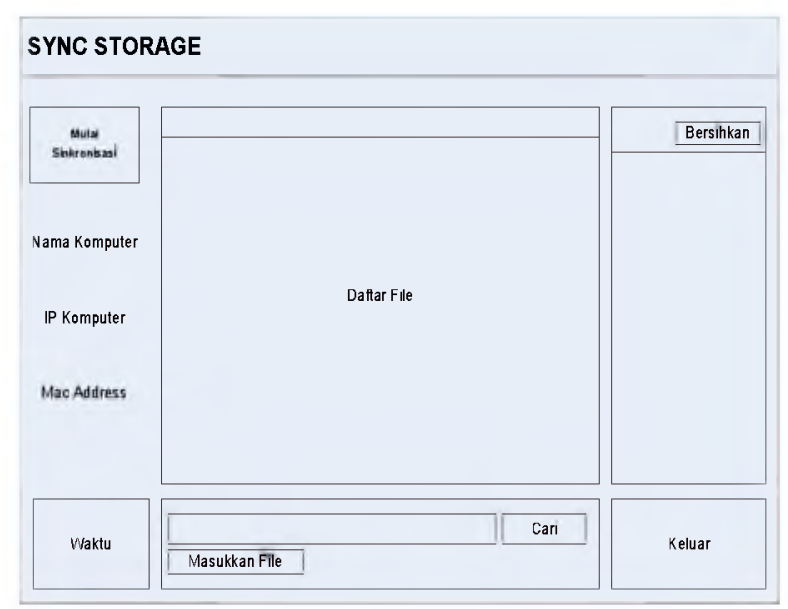

Gambar 2 Tampilan Rancangan Menu Utama 


\subsection{Peralatan Jaringan Komputer}

Penelitian ini membutuhkan peralatan jaringan komputer yang akan digunakan dalam proses uji coba hasil perancangan perangkat lunak sinkronisasi yang menghubungkan tiga buah komputer dalam sebuah jaringan komputer, peralatan tersebut adalah :

1. Switch

2. Modem GSM ( dengan kartu Axis)

\section{Uji Coba}

\subsection{Penjelasan Aplikasi}

Sesuai rancangan pada gambar 1, didapat hasil penerapan aplikasi sinkronisasi seperti pada gambar 2 dan dapat dijelaskan sebagai berikut

1. Setelah program ini dijalankan dan berhasil memasukkan email dan password sesuai akun yang dimiliki, makan akan muncul tampilan utama aplikasi ini seperti pada gambar 3 .

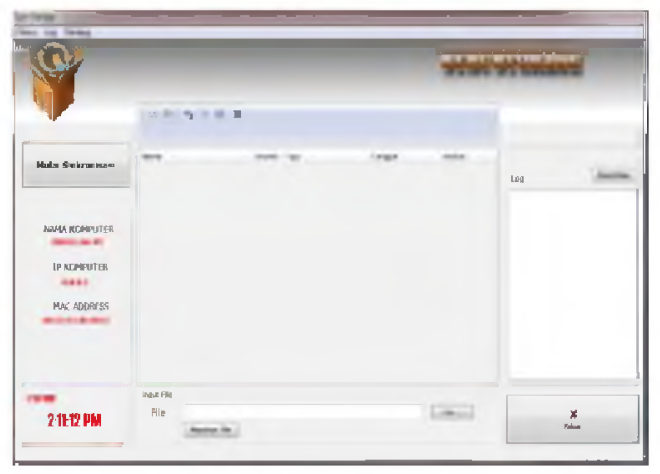

Gambar 3 Tampilan Menu Utama

2. Langkah selanjutnya adalah dengan memasukkan file yang ingin disinkronisasikan dengan cara menekan tombol "Masukkan File" dan memasukkan key administrator sebagai otentifikasi dalam menjalankan proses enkripsi dan input file.

3. Kemudian menekan tombol "Mulai Sinkronisasi" untuk memulai proses sinkronisasi dari computer lokal ke server.

4. Kemudian untuk mengecek keberhasilan proses sinkronisasi pada computer 2 dengan cara menjalakan aplikasi sinkronisasi dengan akun yang sama. Setelah masuk ke menu utama pada computer 2 yang dilakukan adalah menekan tombol "Mulai Sinkronisasi" dan file yang di tambahkan pada computer 1 akan bertambah pada computer 2 .

5. Kemudian untuk proses hapus file yaitu dengan cara menghapus file yang ada di computer 1 dengan memilih file dan klik kanan "hapus file", serta menekan tombol "Mulai Sinkronisasi".

6. Pada Komputer 2 tekan kembali tombol "Mulai Sinkronisasi" maka file yang dihapus pada computer 2 akan ikut terhapus.

7. Sedangkan untuk proses deskripsi yaitu pada saat membuka file dengan cara memilih file kemudian klik kanan "Buka File". Kemudian memasukkan key administrator sebagai otentifikasi dan proses deskripsi akan berjalan. 


\subsection{Uji Coba LAN}

Uji coba LAN dilakukan dengan menggunakan 3 buah computer, 1 komputer dijadikan server dan 2 buah computer dijadikan klien. Uji sinkronisasi dilakukan dengan cara menambahkan file pada computer 2 dan di cek kedalam komputer 3. Grafik hasil dari uji coba singkronisasi dapat dilihat pada gambar 4.

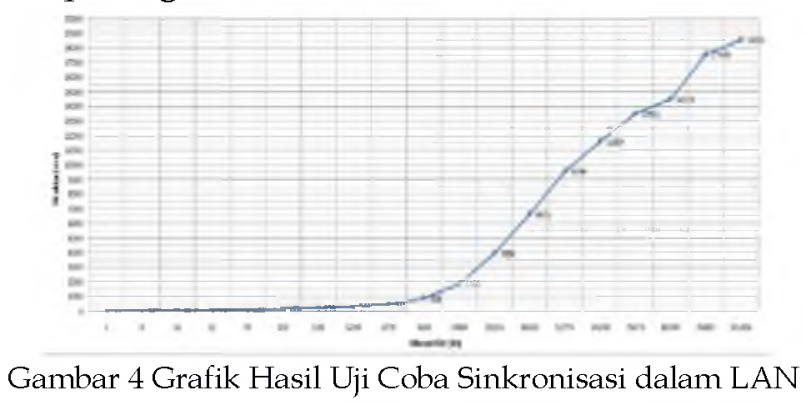

\subsection{Uji Coba Internet}

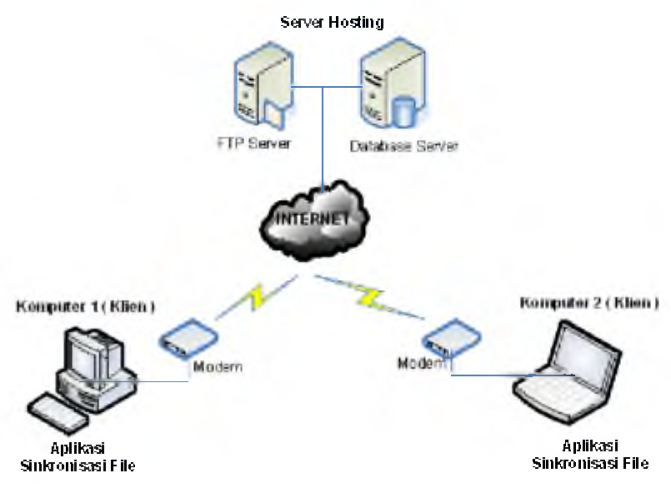

Gambar 5 Skema Uji Sinkronisasi File Dengan Internet

Uji coba internet dilakukan dengan menggunakan 2 buah computer klien, sebuah server hosting yang dijadikan server. Uji sinkronisasi dilakukan dengan cara menambahkan file pada computer 1 dan di cek kedalam computer 2. Grafik hasil dari uji coba singkronisasi dapat dilihat pada gambar 6 .

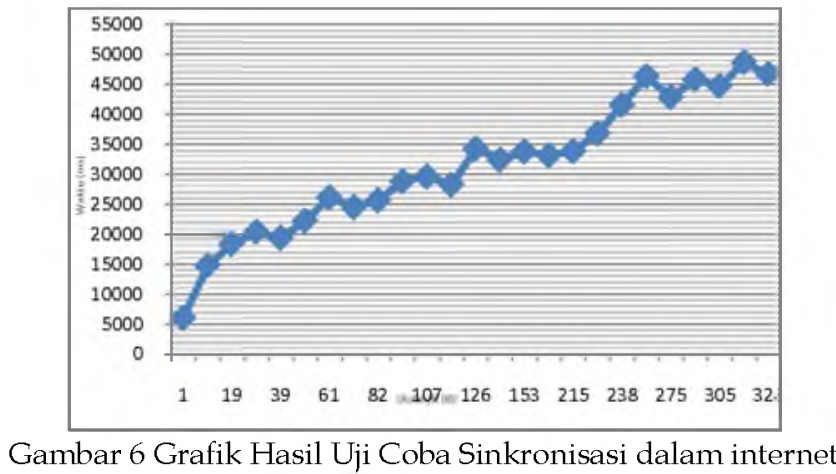

\subsection{Uji Coba Kriptografi}

Uji kriptografi merupakan pengujian terhadap file yang akan diinputkan ke dalam aplikasi sinkronisasi file. Pengujian dilakukan untuk mendapatkan data waktu proses enkripsi deskripsi dan ukuran file sebelum dan sesudah enkripsi. Pengujian kriptografi meliputi 
proses enkripsi pada input file dan proses deskripsi pada open file. Berikut hasil proses enkripsi ditampilkan pada grafik gambar 7 .

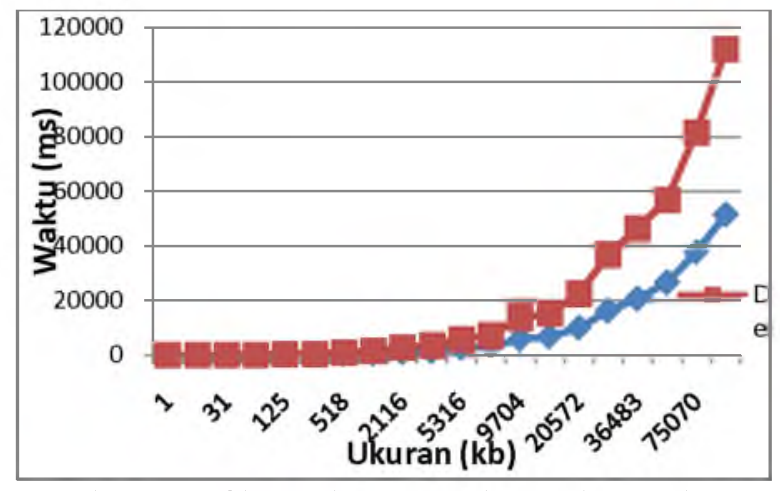

Gambar 7 Grafik Hasil Proses Enkripsi dan Deskripsi

\section{Analisa Hasil Uji Coba}

Dari pengujian yang telah dilakukan dengan 2 jenis proses pengujian, yaitu pengujian sinkronisasi dan pengujian kriptografi diperoleh analisa dari hasil uji fungsi tersebut.

Uji coba yang pertama adalah uji coba sinkronisasi data dilakukan dengan menggunakan 3 buah komputer, 1 komputer dijadikan sebuah server dan 2 buah komputer dijadikan sebagai klien dihubungkan dalam jaringan lokal dengan media transmisi kabel LAN dan sebuah switch dengan maksimum 100 Mbps. Sinkronisasi dilakukan dalam pemindahan data dari komputer 2 ke komputer 3 dan kebalikannya dari komputer 3 ke komputer 2 melalui komputer server. Pada ukuran file kecil antara 1 - $1000 \mathrm{~kb}$ membutuhkan waktu kurang dari 0,3 detik, kemudian pada ukuran file 1000kb membutuhkan waktu 0,5 detik, dan ukuran file diatas $1000 \mathrm{~kb}$ dengan kenaikan ukuran file sebesar $10000 \mathrm{~kb}(10 \mathrm{Mb})$ rata-rata menghasilkan estimasi waktu sekitar $2000 \mathrm{~ms}$ (1detik). Sehingga kecepatan rata - rata proses sinkronisasi file pada jaringan LAN yaitu $5000 \mathrm{~kb}(5 \mathrm{Mb})$ setiap 1 detik.

Sedangkan ujicoba sinkronisasi pada jaringan internet dilakukan dengan 2 komputer klien dan sebuah layanan hosting sebagai server dengan menggunakan koneksi modem kecepatan maksimal $128 \mathrm{Kbps}$. Dari hasil ujicoba proses sinkronisasi berjalan tidak teratur. Hal tersebut disebabkan kecepatan koneksi internet yang dipakai tidak stabil, sehingga waktu yang digunakan dalam melakukan proses sinkronisasi juga tidak stabil. Saat koneksi lambat proses sinkronisasi menjadi lebih lama pula. Oleh karena itu kecepatan proses sinkronisasi pada jaringan internet sangat tergantung pada kestabilan koneksi jaringan internet yang dipakai.

Dari hasil kedua ujicoba pada LAN dan internet dalam melakukan proses sinkronisasi file memunculkan tabel kecepatan perpindahan data yang dapat dilihat pada tabel 1 dan 2 .

Tabel 1 Kecepatan perpindahan data per ukuran file $(\mathrm{Mb})$

\begin{tabular}{|c|c|r|r|}
\hline \multirow{2}{*}{ No } & \multirow{2}{*}{ Ukuran File $(\mathrm{Mb})$} & \multicolumn{2}{|c|}{ LAN } \\
\cline { 3 - 4 } & & Waktu & Kecepatan \\
\hline 1 & \pm 1 & 0.3 & 3.3 \\
\hline 2 & \pm 5 & 1 & 5 \\
\hline 3 & \pm 10 & 2 & 5 \\
\hline 4 & \pm 50 & 10 & 5 \\
\hline
\end{tabular}




\begin{tabular}{l|l|l|}
$5 \mid$ & \pm 100 & $19 \mid$
\end{tabular}

Tabel 2 Kecepatan perpindahan data per ukuran file $(\mathrm{Kb})$

\begin{tabular}{|c|c|r|r|}
\hline \multirow{2}{*}{ No } & Ukuran File & \multicolumn{2}{|c|}{ Internet } \\
\cline { 3 - 4 } & $(\mathrm{Kb})$ & Waktu & Kecepatan \\
\hline 1 & \pm 10 & 15 & 0.67 \\
\hline 2 & \pm 50 & 22 & 2.27 \\
\hline 3 & \pm 100 & 30 & 3.33 \\
\hline 4 & \pm 200 & 35 & 5.71 \\
\hline 5 & \pm 300 & 49 & 1.12 \\
\hline
\end{tabular}

Berdasarkan analisa yang telah diperoleh dapat diambil kesimpulan bahwa kecepatan proses sinkronisasi file dipengaruhi beberapa faktor, yaitu ukuran file dan kecepatan dari koneksi yang dipakai, serta kecepatan proses sinkronisasi berbanding lurus dengan ukuran file yang digunakan.

Uji coba selanjutnya yaitu uji coba kriptografi AES pada aplikasi sinkronisasi file. Uji coba dilakukan pada saat memasukkan file untuk mengetahui waktu enkripsi dan saat membuka file untuk mengetahui waktu deskripsi. Berdasarkan uji coba yang dilakukan bahwa pada ukuran file kecil (kurang dari $1 \mathrm{Mb}$ ) waktu yang diperlukan untuk proses enkripsi hampir sama dengan waktu deskripsi, namun setelah ukuran file mencapai lebih dari $2 \mathrm{Mb}$ waktu yang diperlukan pada proses enkripsi dan deskripsi mulai menunjukkan perbedaan. Setiap kenaikan ukuran file sebesar $5 \mathrm{Mb}$, waktu enkripsi lebih cepat 1 detik dari waktu deskripsi. Berikut contoh dari hasil proses enkripsi dan deskripsi dari file dengan tipe gambar (jpg) seperti pada gambar 8.1, gambar 8.2 dan gambar 8.3 .
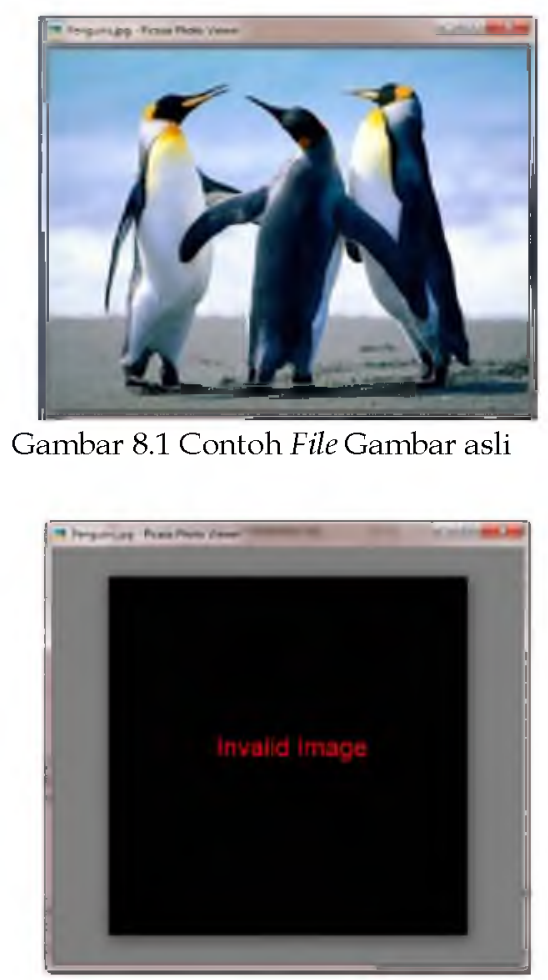

Gambar 8.2 Contoh Gambar telah dienkripsi 


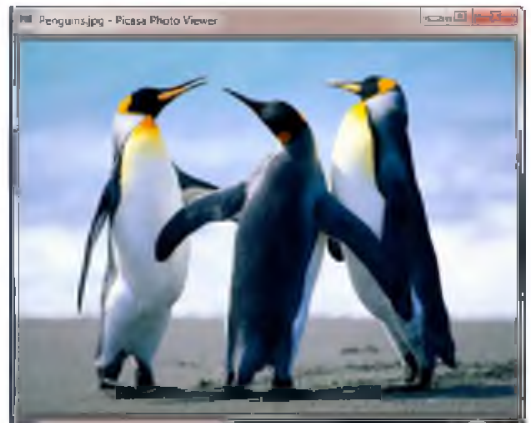

Gambar 8.3 Contoh File Gambar telah dideskripsi kembali

Dari analisa yang dilakukan dapat disimpulkan bahwa menunjukkan kecenderungan kenaikan waktu yang dibutuhkan untuk melakukan proses enkripsi dan dekripsi. Semakin besar ukuran suatu file maka semakin lama pula waktu yang dibutuhkan untuk melakukan proses enkripsi dan proses dekripsi

\section{Kesimpulan}

Kesimpulan yang diperoleh dari hasil analisa pengujian aplikasi sinkronisasi file adalah sebagai berikut :

1. Aplikasi yang dirancang dalam tugas akhir ini dapat digunakan sebagai aplikasi untuk mensinkronisasikan file didalam suatu directory lokal antara dua komputer client yang berbeda dengan menggunakan satu akun yang sama serta juga dapat dijadikan layanan back-up data-data client yang tersimpan di server atau internet.

2. Penggunaan kriptografi AES dan key administrator memberikan keamanan terhadap aplikasi sinkronisasi dan terhadap file yang disinkronisasikan.

3. Faktor koneksi jaringan dan ukuran file menjadi faktor yang mempengaruhi proses sinkronisasi. Didalam jaringan internet diperlukan bandwith yang cukup besar agar proses sinkronisasi file dapat berjalan dengan lancar. Dan semakin besar ukuran file yang disinkronisasikan semakin besar estimasi waktu yang dibutuhkan pada proses sinkronisasi dan proses kriptografi AES yang terjadi.

Selain kesimpulan, penelitian ini juga memiliki saran yang dapat digunakan untuk pengembangan dan penelitian selanjutnya yang terkait dengan penelitian ini. Saran tersebut antara lain:

1. Aplikasi sinkronisasi file ini dapat dikembangkan lagi didalam berbagai platform, misalnya dapat berjalan di sistem operasi linuk, berbasis web bahkan berbasis mobile (android, iphone, windows phone).

2. Apabila dijalankan pada jaringan internet dengan koneksi jaringan yang lambat, diperlukan penambahan suatu sistem untuk kompress data agar ukuran file dapat diperkecil sehingga proses sinkronisasi dalam berjalan lebih cepat dan efisien.

\section{Referensi}

[1] Husni, Membuat Aplikasi Database Client-Server dengan Delphi dan MySQL, Graha Ilmu, Yogyakarta, 2004.

[2] Kristanto, Andri., Keamanan Data Pada Jaringan Komputer, Gava Media, Yogyakarta, 2005. 
[3] Rafiudin, Rahmat., Membangun Server FTP, Andi Offset, Yogyakarta, 2005.

[4] Sadikin, Rifki., Kriptografi Untuk Keamanan Jaringan, Andi Offset, Yogyakarta, 2012.

[5] Stallings, William., Operating Systems: Internal and Design Principles, Fourth Edition, Prentice-Hall International, New Jersey, 2001.

[6] Stallings, William., Cryptography and Network Security, Fourth Edition, Pearson Education, New Jersey, 2006.

[7] Wintolo, Hero., Sinkronisasi Data pada Tabel yang Tersimpan di Dua Database Server yang Berbeda, Jurnal Ilmiah Angkasa Volume II, Nomor 1, Mei 2010.

[8] (30 Mei 2012) http://id.hicow.com/perangkat-selular/sinkronisasi-data/file-data592152.html

[9] (10 Juni 2012) http://rendramm2.wordpress.com/2012/01/17/program-enkripsi-filedengan-metode-aes-menggunakan-delphi-7-part-1/

[10] (10 Juni 2012) $\quad$ http://www.teddybdg.wordpress.com/Delphi/Index.php 